\title{
EL CÓDIGO VESTIMENTARIO CABALLERESCO DE LANZAROTE DEL LAGO DE CHRÉTIEN DE TROYES
}

\author{
$M^{a}$ Jesús Salinero Cascante* \\ Universidad de La Rioja
}

\begin{abstract}
RESUMEN: Partiendo de la importancia social y simbólica que el universo épico medieval concede al ropaje caballeresco, hemos analizado el código vestimentario de Lanzarote. Del mismo modo que el equipamiento guerrero (caballo, armas, armadura, enseñas) es signo del status moral y social del caballero, el desvestimicnto del mismo es signo evidente de su decadencia espiritual
\end{abstract}

RESUME: Nous avons analysé le code vestimentaire de Lancelot tout en tenant compte de l'importance sociale et symbolique que l'univers épique accorde à l'habillement chevaleresque.

De la même façon que l'équipement guerrier (cheval, armes, armure, enseignes) est signe d'un status moral et social du chevalier, le déshabillement devient signe évident de sa décadence spirituelle.

El interés que nos guía en el presente artículo es el de mostrar la estrecha vinculación que existe entre el ropaje caballeresco y el status moral del caballero que lo reviste ${ }^{1}$. La vestimenta posee en el medievo una significación social y simbólica inportante; la armadura, las armas en cuanto que "traje" caballeresco tienen también su valor concreto dentro del universo épico ${ }^{2}$. Del mismo modo que las armas participan de la gloria del caballero mereciendo, en ocasiones, una identidad propia ${ }^{3}$, pueden ser también reflejo

-Dra. en Filología Francesa. Departamento de Lenguas Modernas. Universidad de la Rioja.

1. Consideramos "ropaje caballeresco" todo lo que forma parte de la "in-vestidura" del caballero: armas, amadura y caballo. "Dans une société où 1 habit fait le moine, où le semblant se doit de n"être jamais "faux-semblant", le vêtement se charge d une signification essentielle, puisque au même titre que le nom, il définit celui qui le porte" (Ribard, Le MoyenAge. Littérature et symbolisme. Paris. H. Champion. 1.984, p. 138).

2. Vid. Marc Bloch, La société féodale. Paris. Albin Michel. 1.968. La vestimenta permite evaluar la situación social y espiritual de un personaje determinado.

3. De sobra conocidas son las espadas de Carlomagno (Joyeuse), de Roland (Durendal), del Cid (Tizona)..., o los caballos de Carolomagno (Tencendor), del Cid (Babieca)... 
de su decadencia por su estado, su color, su carencia total o parcial... Como es la excepción la que confirma la regla, nuestro estudio se limitará a los aspectos negativos del código vestimentario. Para ejemplificarlos, hemos elegido a uno de los héroes de Chrétien de Troyes, Lanzarote del Lago ${ }^{4}$. Su pasión por la reina Ginebra lo domina por completo lesionando gravemente su persona heroica y su decadencia se manifiesta a través del ropaje caballeresco, lo que es lógico, por otra parte, si tenemos en cuenta que la caída moral $^{5}$ de Lanzarote se enuncia por medio de la caballería y su código.

En el bosque, ese espacio de nadie ${ }^{6}$, Lanzarote va a cambiar su destino al aceptar la invitación del enano. Subir a la carreta "infamante" representa dejar atrás los valores y actitudes que definen y rigen la sociedad caballeresca para seguir al amor (cf. vv. 365 y ss.). Este abandono del que hablamos no sólo supone un cambio sustancial del caballero que debe iniciarse en una nueva doctrina y cumplir los mandamientos de Amor, sino la pérdida de ciertos atributos que lo definen. Así, Lanzarote aparece en el bosque sin caballo (su caballo ha muerto y, con él, el aliado ficl al servicio de los valores heroicos), sin lanza (arma vinculada especialmente a su persona que lo identifica con el dios irlandés Lug) ${ }^{7}$ y, aunque conserva su espada y su escudo, estos están ceñidos en estado de reposo, signo evidente de que la virtus está detenida, inmovilizada. Como veremos, la desnudez se hace progresiva a medida que Lanzarote avanza en su entrega al otro, a Ginebra ${ }^{8}$.

\author{
le chevalier tot seul a pié, \\ tot armé, le hiaume lacié, \\ l'escu au col, l'espee ceinte, \\ si ot une charrete atainte. (vv. 317-20)
}

En el paso del vado, Lanzarote es retado y atacado por su guardián, sin embargo, su ensimismamiento amoroso le impide oir y responder al ataque, cayendo al agua y perdiendo momentáneamente la lanza y el escudo que son llevados por la corriente (vv.

4. Citaremos por la edición de Mario Roques: Les Romans de Chrétien de Troyes. III. 'Le Chevalier de la Charrette'. Paris. Honoré Champion (col. C.F.M.A.). 1.975.

5. Como creemos haber demostrado en nuestro estudio (Para una antropología de lo imaginario en 'Le Chevalier de la Charrette' de Chrétien de Troyes. Universidad de Zaragoza. 1.991), Lanzarote sufre un verdadero "síndrome catamorfo" provocado por su pasión por la reina. La caída moral tiene su fundamento en la relacción adúltera, agravada considerablemente por ser Ginebra la mujer del rey. La reina representa simbólicamente a la Madre de la sociedad artúrica, del mismo modo que Arturo representa al Padre, lo que abre la puerta al incesto.

6. Espacio marginal, espacio otro, donde no imperan los códigos sociales-caballerescos. El bosque es, incluso, la antítesis del mundo social y civilizado.

7. Chrétien concede importancia a la pérdida de la lanza porque versos después insiste : "Li chevaliers a pié, sanz lance, / aprés la charrete s' avance...", vv.345-6. Desde el punto de vista semántico, Lanzarote no es un nombre inventado por Chrétien, ni tampoco por Ulrich von Zatzikhoven, en su Lanzelet. Algunos críticos han intentado descubrir su significado. Markale establece una relación entre Lanzarote y Lug. Para su comparación se basa, por un lado, en la relación entre los nombres: "Lance-Lot" sería una adaptación de Lug Lamfada "portador de la lanza"; por otra lado, en el papel marginal (Lanzarote nunca llega a integrarse del todo en el mundo artúrico) y multifuncional de ambos. Vid. Markale, Lancelot et la chevalerie arthurienne. Paris. Imago. 1.985, esp. p. 115 y R. S. Loomis, Arthurian Tradition and the Chrétien de Troyes. New York. Columbia University Press. 1.949.

8. "Ce qui caractérisait la plus haute classe des combattants était l'union du cheval et de l'armement complet" (Bloch, Op. cit., p. 405.). 
836-9). En "el puente de la espada" se ve obligado para franquearlo a abandonar el caballo y las armas, además de quitarse parte de la armadura ("il ne s'est lessiez an pié / souler, ne chauce, n’avanpié." vv. 3.103-4). Este "déshabillement" muestra la ambivalencia del puente, el cual a pesar de ser un símbolo diairético y ascensional ${ }^{9}$ es, al mismo tiempo, el "nexo" con Ginebra, la fuente de su vértigo.

En la "quête" de Galván, Lanzarote aparece junto con sus compañeros completamente desarmado siendo esta, en opinión del narrador, la causa de su captura. El ambiente relajado y festivo que se vive después de la victoria obtenida en el primer enfrentamiento con Meleagante les ha hecho olvidar las armas y, por consiguiente, ese "estar alerta", como dice el Evangelio, porque no se sabe ni el día ni la hora en que el enemigo puede atacar. El reproche por este abandono de las armas se percibe claramente en los versos siguientes:

\author{
...et li suen estoient \\ tuit de lor armes desgarni, \\ et por ce furent escherni, \\ que cil del païs armé vindrent. \\ Ne fu pas mervoille sil prindrent \\ Lancelot, qui desarmez icre. (vv. 4.126-4.131)
}

En el torneo de Noauz su desnudez es ya definitiva, pues no tiene armas ni caballo propios; lo que lleva le ha sido temporalmente prestado por la mujer del senescal de Meleagante .

\author{
Et la dame tantost li baille \\ les armes son seignor, vermoilles \\ et le cheval qui a mervoilles \\ estoit biax et forz et hardiz. (vv. 5.498-5.501)
}

Lanzarote reviste las armas del senescal con el fin de servirse de ellas en el torneo donde estará la reina, sin embargo, muy pronto descubrimos que, a esta primera intención, se añade otra: Lanzarote utiliza la armadura para ocultarse de los caballeros allí congregados. Podría aducirse que quiere cvitar ser descubierto para no comprometer a la mujer que le ha salido fiadora, si no fuera porque a lo largo del relato ha mantenido un pertinaz incógnito ${ }^{10}$ " car par le non conuist an l'ome" ". En oposición a otros héroes, que ansían darse a conocer o que desconociendo su nombre desean conocerlo (Perceval,

9. Vid. Mesús Salinero, Op. cit., pp. 390 y ss.; 467 y ss.

10. La mujer, sin embargo, no le pide que oculte su identidad, sino que vuelva una vez que el torneo haya concluído. Pero lo más importante es que el conocimiento (conoisse) se situa en el plano heroico, en su semantismo positivo. Cf. Ribard, Op. cit., pp. 71 y ss.

11. Chrétien de Troyes, Le Conte du Graal (Perceval), t. I. Ed. de Félix Lécoy. Paris. II. Champion (col. C.F.M.A.). 1.979 , v. 560 . 
Lanzelet y Guinglain en Le Bel Inconu), Lanzarote manifiesta en repetidas ocasiones su voluntad de mantenerse en el anonimato, probablemente consciente de que atraviesa una etapa existencial plenamente mística ${ }^{12}$.

Hemos observado que el tema de las armas prestadas se vincula al de la ocultación y este a su vez dinamiza, por antítesis, el miedo a ser descubierto por personajes "diurnos"13 cuando el que quiere ocultarse está en una situación de decadencia heroica y, por lo tanto, humillante. Esta inquietud se explicita en el discurso en la rima "angoisseconoisse" y, aunque se circunscribe casi siempre a la esfera del protagonista, también afecta a otros personajes que están en parecida situación ${ }^{14}$. Centrándonos en Lanzarote, el primer caso aparece en el episodio de la fuente. Lanzarote acaba de descubrir el peine con los cabellos de Ginebra, su emoción es tal que a punto está de caerse del caballo; cuando se recobra, siente vergüenza ante la posibilidad de que la doncella que le acompaña conozca su amor por la reina, sentimiento que le debilita heroicamente (vértigo).

Ne cuidiez pas que le porcoi

la dameisele l'an conoisse,

et si li grevast et neùst,

se le voir l'en reconeùst; (vv.1.446-9)

Otro ejemplo que resulta igualmente interesante, aunque de registro místico (secreto amoroso), tiene lugar en la noche de amor. Tras despedirse los amantes, Lanzarote regresaa su aposento (vv.4.719-20) y durante el trayecto no encuentra "home qui le conoisse." El hecho de que "conoisse" esté asociado a "angoisse" (a pesar de que la causa sea la separación) y al tema del ocultamiento (para un héroe solar al servicio de los valores diurnos, el ocultamiento es negativo y en este caso se trata de silenciar un adulterio) está evidenciando la decadencia heroico-moral de Lanzarote ${ }^{15}$.

También puede suceder que la "angoisse" aparezca a veces del otro lado, del de los caballeros que, queriendo conocer la identidad de Lanzarote, fracasan. Esto ocurre durante el torneo de Noauz ("li chevaliers qu'il ne conoissent./ Trestuit de demander

12. Esto justificaría la ocultación de su nombre y el sobrenombre de "El caballero de la carreta", es decir, de aquel que puso el amor por encima del honor y de la fama de caballero.

13. Utilizamos el término "diumo" en el sentido de "solar", "uraniano" y, por consiguiente, heroico. Cf. G. Durand, Structures Anthropologiques de L 'imaginaire. Paris. Bordas. 1.990, 10 éd.

14. Este es el caso de la doncella de la "encrucijada" cuando implora piedad a Lanzarote para su amigo vencido Et cele en a honte et angoisse qu'ele cuida qu'il la conoisse; car ele ne le volsist pas. (vv. 925-7)

15. Debemos mencionar también otra ocurrencia de la rima "angoisse-conoisse" que, aunque no atañe directamente a la oposición ocultación vs re-conocimiento, incide en el tema del miedo a ofrecer una imagen de decadencia. Cuando Lanzarote, que ha cruzado el puente de la espada, ve llegar a Baudemagus se pone de pie para recibirlo a pesar del tormento que le causan sus heridas. El narrador nos dice que no es porque loconozca sinopara ocultar su dolor (Cf. vv. 3.321-2). Aunque el dolor-angustia no aparece aquí en relación directa con el conocimiento, sí que se articula por el eje dolor-amor propio ante la posibilidad de of recer una imagen en desacuerdo con la del gran héroe que acaba de superar la más grande hazaña. "L'orgueil est un des ingrédients essentiels de toute conscience de classe. Celui des 'nobles' de l'ère féodale fut, avant tout, un orgueil guerrier" (Bloch, Op. cit., pp. 406-7.). 
s'angoissent", vv. 5.633-5) y al final del mismo ("car il s"an fuit, / qu'il n'a cure qu'an le conoisse. / Grant duel en ont et grant angoisse / li chevalier..." vv. 6.043-5). La persistencia del héroe en mantener su anonimato, incluso ante el triunfo, nos confirma que no es merecedor todavía de manifestarse publicamente ante la corte artúrica.

En fin, los ejemplos expuestos son suficientemente ilustrativos de que existe un sentimiento generalizado de vergüenza, de pudor ante la posibilidad de darse a conocer o de evidenciar un sentimiento, actitud que se consideraría degradante en el ámbito caballcresco. Así mismo, hemos visto que, cuando el reconocimiento heroico es abortado por propia iniciativa del protagonista se genera en el campo de lo social un estado de ansiedad. Este malestar, que vemos en unos y otros casos, tan sólo puede atribuirse al autor (Lanzarote es cl amante perfecto), cuya mente esencialmente diurna rechaza el comportamiento amoroso de su personaje. Así pues, primero con el incógnito (nombre), segundo con el disfraz (armadura), Lanzarote efface su persona caballeresca, es decir, el disfraz no oculta una realidad interior sino que se constituyc en reflejo de ella operándose, por consiguiente, una duplicidad y al mismo tiempo una inversión funcional de la máscara, pues, si "le masque, comme tout déguisement, sert à changer ou à obliterer la realité", es decir, produce "une illusion de la realité, une fausse semblance"16, en Lanzarote traducc la transformación interior por la que lo que parece es. En el Tristan de Eilhart von Oberg sucede otro tanto; los disfraces que Tristan utiliza en la segunda parte de la obra son conformes, por su marginalidad (leproso, juglar, loco), a su situación de exilado gozando de un amor adúltero y, por lo tanto, peligroso ${ }^{17}$. Como dice V. Hugo en Mille francs de récompense:

Déguisements, travestissements, dominos. On appelle cela se masquer. C'est tout le contraire. Tous ces gens-là viennent ici $s^{\prime}$ appliquer sur la face le vrai visage qui ne trompe pas.

La utilización de una armadura y de unas armas que no le pertenecen es indicativa de decadencia diurna, de transgresión, pues como señala J. Le Goff, "porter celui (vêtement) d'une autre condition que la sienne, c'est commeture le péché majeur d'ambition ou de décheance"18. El tema de las armas prestadas aparece ya en Erec, cuando el protagonista se vale de las armas del padre de Enide ${ }^{19}$-un valvasor empobrecido (decadencia material)- para competir por cl "gavilán"20. Mucho más interesante es

16. Bembowski, "Le faux semblant et la problématique des masques et déguisements" en Masques et déguisements dans la littérature médiévale. Montréal. Vrin. 1.988, pp. 45-53 (p. 43).

17. Cf. D. Buschinger, "Le motif du déguisement de Tristan dans les oeuvres médiévales allemandes des XII et XIII siècles" en Masques et déguisements dans la littérature médiévale, pp. 35-45.

18. J. Le Goff, La civilisation de l'occident médiéval. Paris. Arthaud. 1.987, p. 400.

19. Cf. Chrétien de Troyes, Erec et Enide (éd. de Mario Roques). Paris. H. Champion (col. C.F.M.A.). 1.979, vv. 375 $376 ; 485-89 ; 512-17$. Sobre el tema del disfraz en el universo caballeresco remitimos al valioso estudio de Marco Infuma sobre Guillaume d'Orange, "Il motivo del travestimento nel ciclo di Guillaume d'Orange" en Medioevo Romanzo, X, 3, 1.985, pp. 349-369. En Guillaume el disfraz cumple, por contraste (efecto irónico), una función exaltadora de la caballería y de los caballeros.

20. Con estas armas conquista al pájaro y, con él, a la mujer (Énide). 
la apropiación de las armas del Caballero Bermejo por parte de Perceval. La concordancia simbólica de estas armas con las armas de Lanzarote en el torneo es sorprendente. Lanzarote lleva unas armas nuevas: "armez d'unes armes molt beles, / trestotes fresches et noveles" (vv. 5. 503-4) y el Caballero bermejo (y posteriormente Perceval) también: "Li vaslez vit les armes beles, / qui totes estoient noveles" (vv. 871-872).

El color de la armadura de Lanzarote es rojo: "les armes son seignor, vermoilles" (v. 5.499); el mismo color del Caballero Bermejo al que le sirve, incluso, de identificación ("li Vermauz Chevaliers a nom" v. 948): "qui totes vermoilles estoient" (v. 870). ¿Cuál puede ser el sentido de los epítetos "noveles" y "vermoilles"?. ¿Qué nos está señalando Chrétien en relación con el caballero que las posee?. Para responder analizaremos con más detalle el episodio del torneo. Comencemos por el heraldo y su actitud ante las armas de Lanzarote. Los heraldos tenían dentro del universo caballeresco, entre otras funciones, la de registrar los nombres y los blasones de los caballeros ${ }^{21}$, lo que los convertía en personas especialmente versadas en las distintas enseñas de las gentes de caballería. Resulta fácil comprender su desconcierto cuando descubre colgado a la entrada de una tienda un escudo que le es desconocido: "escu trova... /... mes ne pot estre / qu 'il coneüst lui ne son mestre, / ne set qui porter le devoit" (vv. 5.542-50). La sorpresa del heraldo nos indica que se trata de unas armas "ajenas" a la caballería mundialmente renombrada, la cual, posteriormente, será objeto de una descripción minuciosa ${ }^{22}$ sirviendo de contraste a esas "fresches ct noveles" armas del Caballero Bermejo. Con toda probabilidad, ambos adjetivos indican que se trata de armas que todavía no han alcanzado su sello de gloria y que, por lo tanto, no han prestado servicio a los valores transcendentales.

Ante su desconocimiento, el heraldo tiene necesidad de ver a su ducño, así que entra en la tienda reconociendo a Lanzarote porque este se ha "des-vestido" de su armadura. Nótese la relación causal que se establece entre ver y conocer ${ }^{23}$.

Lanceloz trestoz desamez

... et vit gesir el lit

Lancelot, et puis qu'il le vit

le conut, et si s’an seigna. (vv. 5.533-5.549)

Su desnudez heroica, doblemente determinada por su desnudez real y por la falta de unas armas propias, es aquí en el torneo total; en el episodio del bosque, su semidesnudez (no aceptada voluntariamente) ${ }^{24}$ había simbolizado la minimización de sus virtudes diurnas, ahora su desnudez representa una ocultación (cn este caso deseada,

21. Otras funciones eran anunciar los tomeos y organizar las "fiestas" de la caballería.

22. Aquellos que no participan en el tomeo describen a las damas asistentes al mismo los blasones y las enseñas de los caballeros más importantes y de más valor. "Ensi devisent et deboissent / les armes de ces qu il connoissent" vv. 5.8234). Sin embargo, del caballero "Qu'il ne conoissent" se preguntan "Qui est il?" (v. 5.619).

23. Vid. también vv. 5.534-49.

24. Todo hace suponer que en el bosque, Lanzarote pierde su caballo y su lanza en el enfrentamiento con Meleagante, fuerza tenebrosa llegada de otro mundo. Cf. nuesto estudio, Op. cit., cap. "La lucha en el bosque". 
como demuestra la prohibición expresa que Lanzarote hace al heraldo) de su naturaleza luminosa:

... mes herbergier ne voloit pas

an leu ou il fust coneüz. (vv.5.510-11)

Et Lancelot le regarda, et desfandi qu'il ne parlast

de lui, an leu ou il alast... (vv.5.548-5.555)

Lanzarote está en fase lunar ("Chez le héros solaire, ce sont les exploits qui comptent plus que sa soumission à l'ordre d'un destin" ${ }^{25}$ ) y su decadencia heroica se subraya a través de la decadencia material del decorado y de la decadencia del propio heraldo.

La probreza y tenebrosidad del hospedaje -realzada con el intensivo molt- no corresponde al de un caballero, pero Lanzarote no ha querido albergarse en la ciudad donde le habrían reconocido ("mes herbergier ne voloit pas / an leu ou il fust coneiiz" vv. 5.510-11):

Einz si prodom n'ot mes itel car molt estoit petiz et bas (vv.5.508-9) en un lit qu il molt po prisoit qu'estroit ert, et la coute tanve coverte d'un gros drap de chanve (vv. 5.530-2)

Por otra parte, Lanzarote es reconocido por un servidor, que además se encuentra, él mismo, en un lamentable estado.

un hyraut d'armes, an chemise, qui an la taverne avoit mise sa cote avoec sa chauceüre, et vint nuz piez grant aleüre, desafublez contre le vant; (vv. 5.537-41)

Su desnudez denuncia su propia decadencia moral y es reflejo de la de Lanzarote (esta función especular le convierte en un personaje isomorfo del enano de la carreta ${ }^{26}$ ); su proveniencia de la taberna -decorado nocturno donde se asocian los símbolos alimentarios, la bebida (imágenes de embriaguez) y el dinero que se juega- nos lo

25. Durand, Structures Anthropologiques..., p. 179.

26. Al dejar Lanzarote a un lado su orgullo de clase y prestarse dócilmente a la manipulación del enano se opera una transferencia de imágenes: Lanzarote, guiado por su parte instintiva (pasión), asume la pequeñez del homonculus con sus valores otros (minimización de los valores heroicos y transcendentales). Efectivamente, Lanzarote aparece como un ser degradado, leproso social y espiritual, que debe ser marginado (recuérdese que esta era la consecuencia que acarreaba subir a la carreta). 
identifica como un producto de este mundo nocturno y marginal ${ }^{27}$, como un ser contaminado por los valores ctónicos, que nunca son atractivos para una perspectiva épica. El color rojo de las armas ("vermoille") confirma, por otro lado, que Lanzarote, al igual que Perceval, se halla en una fase emotivo-instintiva ${ }^{28}$; en el caso de $L a$ Charrette, el héroe está poseído por un ánima negativa ${ }^{29}$.

Existe también una estrecha relación entre el propietario real de las armas y su usurpador, y entre los propietarios entre sí. Tanto en Le Graal como en La Charrette, el caballero bermejo y el senescal (por medio de su señor Meleagante ) están vinculados al tema del ultraje inferido al rey Arturo por medio de la reina Ginebra: el primero derrama sobre la reina el vino de la copa del rey; cl segundo (Melcagante) se lleva a la reina a su país, Gorre, en calidad de prisionera; ambos están poscídos por la fuerza instintiva incontrolada, en ambos su decadencia espiritual es evidente ${ }^{30}$.

En cuanto a los "usurpadores", Perceval aparece -debido probablemente a su aislamiento- como un muchacho dominado por fuerzas ciegas que le arrastran y le impiden conocer el alcance de su conducta egoísta, y del pecado cometido por la falta de caridad mostrada hacia su madre cuando cayó muerta ${ }^{31}$. La situación moral de Perceval, en el momento de apoderarse de las armas, no difiere grosso modo de la del caballero bermejo: "il y a identitéévidente entre Perceval et Le Chevalier Vermeil, mais tandis que ce dernier semble au terme de sa carrière puisqu il parvient à mettre en péril le Roi et sa cour, Perceval, lui, n'en est encore qu à son commencement"'32. Parece, por lo tanto, que no es una mera coincidencia que Perceval revista armas bermejas como tampoco lo es que estando al inicio de su carrera sean estas "noveles".

Lanzarote, por su parte, ha seguido una doctrina contraria a los ideales de la Transcendencia, lo cual le ha llevado a atentar contra su propia vida ${ }^{33}$, pecado que, en

27 Entre los oficios y lugares que son objeto de condena y desprecio en la Edad Media, Jacques I e Goff (Pour un autre MoyenAge. Paris. Gallimard. 1.978) cita al tabernero y a la tabema (o albergue). Tras el menosprecio de estos "negotia illicita" aparecen los viejos tabúes de las sociedades primitivas, muy activos en el espiritu medieval. La tabema es un lugar de corrupción ya que se comercia con "la triple volupté maudite du vin, du jeu et de la danse" (p. 95). La taberna es, también, lugar de comercio camal.

28. Cf. M. L. von Franz, L'ombre et le mal dans les contes de fées. Paris. La Fontaine de Pierre. 1.980, p. 135. Vid. también Ribard, "Le symbolisme des quatre éléments dans le tournoi d’Osenefort du Cigès de Chrétien" en Les quatre éléments dans la culture médiévale. Université de Picardic. Centre DTtudes Médiévales. Kummerle Verlag. 1.983, pp. 1639 (p. 167).

29. Cf. von Franz, Op. cit., pp. 119-120.

30. Las cualidades épicas de Meleagante que habrian hecho de él un guerrero ejemplar, mal orientadas, se distorsionan convirtiéndose en fuerzas al servicio del Mal: agresividad, crueldad, desmesura, orgullo, felonía.

31 "A la face inconsciente de la vocation s'ajoute en lui l'égoïsme de la jeneusse qui se rit de l'affection de sa mère ... Pas le moindre mouvement de pitié et de charité dans son coeur ... : il faudra qu'il sente le poids de plus en plus lourd des remords, pour qu il s'en libère par le repentir et puisse prétendre à une plus haute perfection, puis, sans doute, au chemin retrouvé du Graal." (J. Frappier, Chrélien de Troyes et le mythe du Graal, París. Sedes. 1979, pp. 80-21.). Cf. así mismo, Ch. Payen, Le motif du repentir dans la littérature française médiévale. Des origines à 1.300. Genève. Droz. 1.968, pp. 391-400; R. Bezzola, Le sens de l'aventure et de l'amour. Chrétien de Troyes. Paris. Champion. 1.968, p. 57 y D. Viseux, L'initiation chevaleresque dans la légende arthurienne. Paris. Dervy-Livres. 1.980, pp. 61, 64.

32. D. Viseux, Op. cit., p. 55.

33. A Lanzarote le llega la falsa noticia de la muerte de Ginebra. Desaparecida la razón de su existencia, Lanzarote decide quitarse la vida pasando la brida del caballo alrededor de su cuello y dejándose caer del mismo. Por fortuna, sus compañeros le salvarán en el último momento. El suicidio es en la Edad Media el pecado de los pecados pues atenta contra la obra creadora de Dios. En el caso de Lanzarote se agrava considerablemente ya que el héroe trata de satisfacer una oscura justicia amorosa (Eros-Thanatos). Vid. Ch. Payen, Op. cit., pp. 283 y ss. 
nuestra opinión, es sancionado posteriormente con la torre. En este estado de cosas, Lanzarote poseído por sus emociones y afectos (esfera instintiva), tampoco difiere de su alter ego Meleagante ${ }^{34}$. Por consiguiente, Lanzarote llega al torneo desde un mundo de sombras (la prisión), ocultándose tras la imaginería de un guerrero luminoso, pero su brillo es superficial ("l"éclat du neuf"), puesto que no emerge del interior del ser. Comparándolo con Perceval, comparación que juzgamos suficientemente justificada por la similitud simbólica, Lanzarote parece haber retrocedido en la senda heroica y perdido la cota alcanzada en el puente de la espada donde logra el reconocimiento unánime de la caballería. Ahora, en el torneo, es un desconocido llevando armas noveles y lo es, en la misma medida que es reconocido y conducido, en el ámbito místico, por su dama. Su decadencia "diurna" vuelve de nuevo a expresarse a través de su desnudez caballeresca, pues, Lanzarote antes de regresar a su prisión, una vez finalizadas las justas, debe desvestir los signos que no le pertenecen y devolverlos a la caballería, la propietaria legítima, en última instancia. La desposesión de por sí significativa, lo es más si pensamos que lo abandonado es el escudo, la lanza y la gualdrapa del caballo, pues en el escudo y en la gualdrapa se mostraban las enseñas de los caballeros. Eran los signos "fastos" del linaje, de la gloria y del reconocimiento adquiridos.

\author{
Mes au departir, son escu \\ leissa an la presse cheoir, \\ la ou greignor la pot veoir, \\ et sa lance et sa coverture; \\ puis si s'an va grant alcüre. (vv. 6.028-32)
}

Posiblemente, este gesto "consciente" de desnudarse marca el punto de partida para su recuperación, para su renacimiento heroico, el cual tendrá lugar despućs del proceso catártico $^{35}$ de la torre. Durante este periodo $\mathrm{el} \mathrm{héroe} \mathrm{se} \mathrm{desviste} \mathrm{del} \mathrm{hombre} \mathrm{viejo,} \mathrm{para}$ revestir después nueva vestidura. El héroe solar aparecerá determinado por una renovación ("tot le renovele... / tot le remue, tot le change" v. 6.668-9) moral que se refleja en la belleza del cuerpo (biax, forz). Lanzarote es un ser puro y, en su pureza, alcanza el viejo sueño de la imaginación aérea, la perfección angélica "or n"est moins biax d'un ange" (v.6.670). Lanzarote ya está preparado para su lucha definitiva contra Meleagante y, por ello, recibe de la hermana de éste la "robe plus bele qu'ele pot" (v. 6.674), un caballo "merveilleus" y de Gauvain las armas, armas prestigiosas (no las armas fresches y "noveles" del torneo) que poseen el poder y la virtud de lo luminoso,

34. "Les figures de héros positifs sont des systèmes de contraires en tension: elles ne se construissent pas sur la seule personne du sujet, mais tout autant sur celles des opposants. Le chevalier à la charrette n'est pas seulement Lancelot, mais Lancelot et Méléagant ... La verité du héros diume se cache aussi dans son double ténébreux" (Chandès, Le serpent, lafemme et l'éppée. Amsterdam. Rodopi. 1.986, p. 208.)

35. En la torre-prisión tiene lugar el proceso expiatorio que purifica al caballero de los pecados y errores cometidos (adulterio, intento de suicidio). En ella Lanzarote se somete a un rito lustral fundamentado en el retiro (exclusión) durante cierto tiempo del universo caballeresco-cristiano y en el ayuno. Cf. M Jesús Salinero, Op. cit., espc. "Ritos de purificación: la torre". 
del Bien. Con ellas Lanzarote alcanza definitivamente cl triunfo y la gloria.

Li rois et tuit cil qui i sont

grant joic an demainnent et font.

Lancelot desarment adonques

cil qui plus lié an furent onques,

si l’en ont mené a grant joic. (vv. 7.093-7)

Resumiendo, del mismo modo que Jcan Györy demostró en su artículo "Prolégomènes à une imagerie de Chrétien de Troyes" 36 que existe en Chrétien un complejo vestimentario, es decir, una imagen obsesiva de la vestimenta, ligado al tema de la "dechéance" material ${ }^{37}$, nosotros consideramos, despućs de lo expuesto, que existe una variante del complejo en relación con la decadencia espiritual: Chréticn expresa la "caída moral" a través del ropaje caballeresco y, cn concreto, a través del "déshabillement chevaleresque" puesto que la caballería es la depositaría de los valores morales de la corte artúrica y, fuera ya de la ficción, de la sociedad feudal. En el caso de Enide y de Perceval, la pobreza de su ropa es el signo de la decadencia paterna; en Lanzarote, en cambio, la pobreza de su ropaje épico es el signo de su decadencia moral. ¿Quiere esto

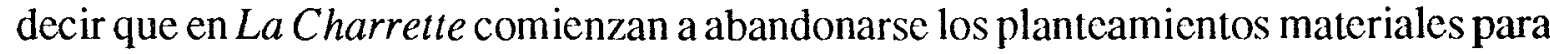
ser reemplazados por otros de índole espiritual?. De ser así, La Charrette supondría el principio de una evolución que se desarrolla plenamente en Le Graal.

36. J. Györy, "Prolégomènes à une imageric de Chrétien de Troycs" dans Cahiers de Civilisation Médiévale. 1.967, pp. 361-384.

37. En su opinión, el complejo sería un fiel refejo de la nostalgia del campesino (Chrétien) que pretende le sean reconocidos sus méritos por haber superado la deficiencia de partida ("Quelqu'un impose ici son moi plébeien ou roturier à la cour royale, on attend la consécration de son talent par les grands: lui, le poète, conscient de ses qualités", art. cit., p. 372 .). 